\title{
The effect of body mass index on perioperative thermoregulation
}

\author{
This article was published in the following Dove Press journal: \\ Therapeutics and Clinical Risk Management \\ 18 November 2016 \\ Number of times this article has been viewed
}

\author{
Ayșe Belin Özer \\ Aysun Yildiz Altun' \\ Ömer Lütfi Erhan' \\ Tuba Çatak ${ }^{2}$ \\ Ümit Karatepe' \\ İsmail Demirel' \\ Gonca Çağlar Toprak ${ }^{3}$ \\ 'Department of Anesthesiology \\ and Intensive Care, Firat University \\ Medical School, Elaziğ, ${ }^{2}$ Department \\ of Anesthesiology and Intensive Care \\ Clinic, Bingol State Hospital, Bingöl, \\ ${ }^{3}$ Department of Anesthesiology and \\ Intensive Care Clinic, Elazig Training \\ and Research Hospital, Elaziğ, Turkey
}

Correspondence: Ayșe Belin Özer Department of Anesthesiology and Intensive Care, Firat University Medical School, Yunus Emre Bulvarı, No 20, Elaziğ 23। I9, Turkey

Tel +904242333555

$\mathrm{Fax}+904242388096$

Email abelinozer@gmail.com
Purpose: We evaluated the effects of body mass index (BMI) on thermoregulation in obese patients scheduled to undergo laparoscopic abdominal surgery.

Methods: Sixty patients scheduled to undergo laparoscopic abdominal surgery with no premedication were included in the study. The patients were classified into 4 groups according to BMI $<24.9,25-39.9,40-49.9$, and $>50$. Anesthesia was provided with routine techniques. Tympanic and peripheral temperatures were recorded every 5 minutes starting with the induction of anesthesia. The mean skin temperature (MST), mean body temperature (MBT), vasoconstriction time, and vasoconstriction threshold that triggers core warming were calculated with the following formulas: $\mathrm{MST}=0.3\left(T_{\text {chest }}+T_{\text {arm }}\right)+0.2\left(T_{\text {thigh }}+T_{\text {calf }}\right)$. MBT was calculated using the equation $0.64 T_{\text {core }}+0.36 T_{\text {skin }}$, and vasoconstriction was determined by calculating $T_{\text {forearm }}-T_{\text {finger }}$. Results: There was no significant difference between the groups in terms of age, gender, duration of operation, and room temperature. Compared to those with BMI $<24$. 9 , the tympanic temperature was significantly higher in those with BMI $=25-39.9$ in the 10th, 15th, 20th, and 50th minutes. In addition, BMI $=40-49.9$ in the 5th, 10th, 15th, 20th, 25th, 30th, 40th, 45th, 50th, and 55th minutes and BMI $>50$ in the 5th, 10th, 15th, 20th, 25th, 30th, 50th, and 55th minutes were less than those with BMI $<24.9(P<0.05)$. There was no significant difference in terms of MST and MBT. Vasoconstriction occurred later, and that vasoconstriction threshold was significantly higher in patients with higher BMIs.

Conclusion: Under anesthesia, the core temperature was protected more easily in obese patients as compared to nonobese patients. Therefore, obesity decreases the negative effects of anesthesia on thermoregulation.

Keywords: anesthesia, obesity, body mass index, thermogenesis

\section{Introduction}

As homeothermic beings, humans require a constant core body temperature. Core body temperature is controlled by the temperature regulation system located in the anterior hypothalamus, and daily change is regulated with $0.2^{\circ} \mathrm{C}$ deviation from normal. While acceptable changes are controlled by the temperature regulation system, significant changes may lead to metabolic dysfunction and even death. ${ }^{1}$

Besides the fact that anesthetic agents inhibit thermoregulation and cause vasodilation, the coldness of the operation room, cleaning of patients with cold solutions, usage of cold and dry gases for ventilation, irrigation of the surgical field with cold fluids, administration of intravenous cold fluids and blood transfusions, and evaporation from the surgical field have nonnegligible contributions to intraoperative or postoperative hypothermia. $^{2}$

Recent studies have shown that mild hypothermia (approximately $1^{\circ} \mathrm{C}-2^{\circ} \mathrm{C}$ ) triple the incidence of cardiac events and surgical wound infections, lengthen the duration 
of hospitalization by $20 \%$, and significantly increase surgical blood loss and related need for blood transfusion. ${ }^{2-4}$

In obese patients, subcutaneous fat tissue and body surface area increase. Based on its known role in thermogenesis, fat tissue (especially brown fat) may affect the incidence of obesity perioperative hypothermia. For this reason, we evaluated the effects of body mass index (BMI) on thermoregulation in obese patients scheduled to undergo laparoscopic abdominal surgery.

\section{Methods}

After approval of the ethics committee (Firat University Ethics Committee on Non-Invasive Research, 13.01.2015/01/04), trial number (ACTRN12615000375550), and written informed consents from patients were obtained, this study was performed at the Firat University Hospital. Sixty patients scheduled to undergo laparoscopic abdominal surgery with no premedication were included in the study. Patients were chosen from cases that took place between 09:00 and 13:00 hours. Patients with high fever, diabetes mellitus, muscle diseases, hypo/hyperthyroidism, Parkinson's disease, Raynaud's phenomenon, and history of drug use that would affect body temperature ( $\beta$-blockers, calcium channel blockers, clonidine, steroids, antiepileptics, and nonsteroidal anti-inflammatory drugs [NSAIDs], benzodiazepines) were not included. Also, patients who underwent a surgery that took $<60$ minutes or $>180$ minutes were not included in the study. Patients whose hemodynamic parameters changed $>30 \%$ during the surgery, or patients who require vasopressors, vasodilators, or blood transfusions were excluded from the study.

The patients were categorized into 4 groups based on their BMI: group I $(n=15)$ : BMI $<24.9$, group II $(n=15)$ : BMI $=25-39.9$, group III $(n=15):$ BMI $=40-49.9(n=15)$, and group IV: $\mathrm{BMI}>50(\mathrm{n}=15)$.

The induction $(2 \mathrm{mg} / \mathrm{kg}$ propofol and $0.6 \mathrm{mg} / \mathrm{kg}$ rocuronium) and maintenance (2\% sevoflurane in $50 \% \mathrm{O}_{2}$ and remifentanil infusion) of anesthesia were achieved with routine methods. Endotracheal intubation was performed for mechanical ventilation at a target end-tidal carbon dioxide value between 35 and $40 \mathrm{mmHg}$. At the termination of surgery, sevoflurane was stopped, and $100 \% \mathrm{O}_{2}$ inhalation was started. Reversal of neuromuscular blockade was achieved with $0.05 \mathrm{mg} / \mathrm{kg}$ neostigmine and $0.01 \mathrm{mg} / \mathrm{kg}$ of atropine sulfate. Perioperative heartbeat (bpm), mean arterial pressure and tympanic, chest, arm, 1/2 medial inner face of forearm, ventral face of the distal phalanx of middle finger, thigh, and calf temperatures were recorded every 5 minutes. Waking up from anesthesia was achieved with routine methods, and patients were taken into the recovery room.

The mean skin temperature (MST), mean body temperature (MBT), vasoconstriction time, and vasoconstriction threshold that triggers core warming were calculated with the following formulas: the $\mathrm{MST}=0.3\left(T_{\text {chest }}+T_{\text {arm }}\right)+$ $0.2\left(T_{\text {thigh }}+T_{\text {calf }}\right){ }^{5}$ The MBT was calculated using the equation $0.64 T_{\text {core }}+0.36 T_{\text {skin }}$, and vasoconstriction was determined by calculating $T_{\text {forearm }}-T_{\text {finger }}=0-4$. The core temperature at the moment of vasoconstriction was used to determine the vasoconstriction threshold. ${ }^{6-9}$

IBM SPSS (Statistical Package for the Social Sciences) version 20 program was used for statistical analyses. The parametric data were taken as mean \pm standard deviation and evaluated with variance analysis, after which independent $t$-test was used for intergroup comparisons. For intragroup comparison, paired sample $t$-test was used. The American Society of Anesthesiology (ASA) risk classes of the groups were evaluated with chi-square test. A $P$-value of $<0.05$ was deemed statistically significant.

\section{Results}

There was no significant difference between the groups in terms of age, gender, duration of operation, and room temperature (Table 1). When compared with group I, tympanic temperature was significantly higher in the 10th, 15th, 20th, and 50th minutes in group II; in the 5th, 10th, 15th, 20th, 25th, 30 th, 40th, 45th, 50th, and 55th minutes in group III; and in the 5th, 10th, 15th, 20th, 25th, 30th, 50th, and 55th minutes in group IV $(P<0.05$; Figure 1$)$. There was no significant difference in terms of MST and MBT (Figures 2 and 3).

Table I Demographic data of patients

\begin{tabular}{|c|c|c|c|c|}
\hline Parameters & Group I & Group II & Group III & Group IV \\
\hline Age (years), mean \pm SD & $46.31 \pm 11.61$ & $37.13 \pm 14.48$ & $36.52 \pm 10.38$ & $38.20 \pm 10.15$ \\
\hline ASA, physical status (I/II/III) & $2 / 14 / 0$ & $0 / 15 / 0$ & $0 / 14 / 1$ & $0 / 13 / 2$ \\
\hline Gender (M/F) & $6 / 9$ & $1 / 14$ & $4 / 11$ & $3 / 12$ \\
\hline Operation duration (minutes), mean \pm SD & $64.69 \pm 12.84$ & $70.33 \pm 21.99$ & $70.33 \pm 12.08$ & $73.50 \pm 10.28$ \\
\hline Room temperature $\left({ }^{\circ} \mathrm{C}\right)$, mean $\pm \mathrm{SD}$ & $21.75 \pm 0.46$ & $21.50 \pm 0.63$ & $21.25 \pm 0.96$ & $21.55 \pm 1.01$ \\
\hline Amount of fluid $(\mathrm{mL})$, mean $\pm S D$ & $1.24 \pm 0.33$ & $1.56 \pm 0.6 \mathrm{I}$ & $1.68 \pm 0.47$ & $1.48 \pm 0.38$ \\
\hline
\end{tabular}

Abbreviations: ASA, American Society of Anesthesiology; M, male; F, female. 


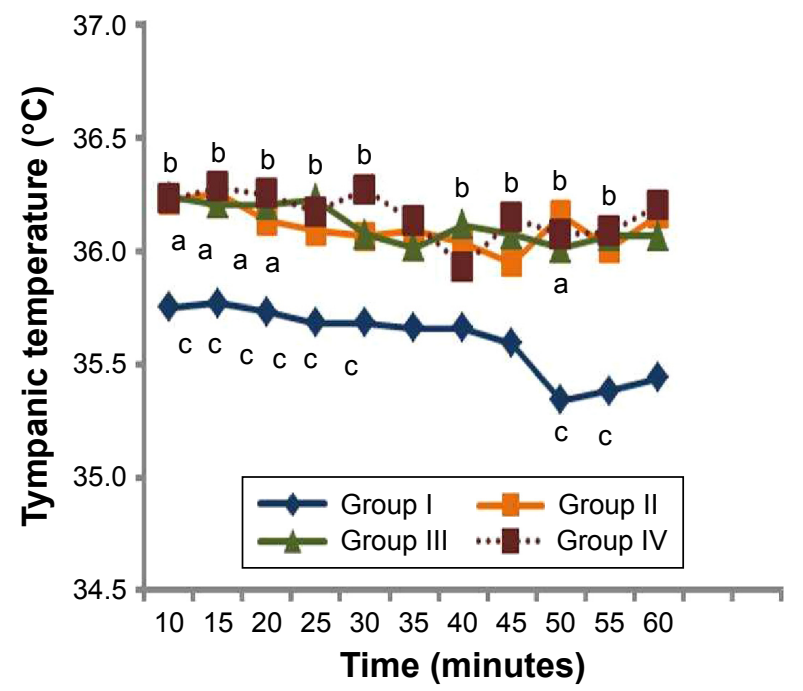

Figure I Tympanic temperatures of the groups $\left({ }^{\circ} \mathrm{C}\right)$.

Notes: $P<0.05$; ${ }^{a}$ Comparisons of group II and group I; broup III and group I; and group IV and group I.

Vasoconstriction occurred later in groups with higher BMIs (in the 10th, 25th, 15th, and 55th minutes, respectively, according to BMI). Vasoconstriction threshold was significantly higher in patients with higher BMIs $\left(35.75^{\circ} \mathrm{C}\right.$, $36.06^{\circ} \mathrm{C}, 36.20^{\circ} \mathrm{C}$, and $36.20^{\circ} \mathrm{C}$, respectively, from groups I to IV). There was no significant difference between the groups in terms of trembling scores, and there was no significant correlation between BMI and trembling.

\section{Discussion}

Anesthesia is one of the practices that tend to create hypothermia by changing the temperature regulation system of the body. Hypothermia development follows a special course during general anesthesia. Core temperature decreases by

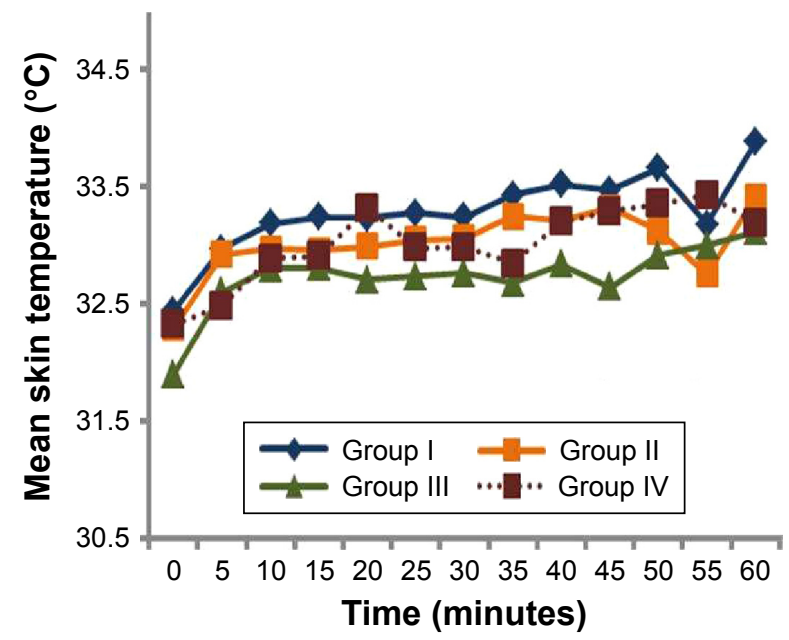

Figure 2 Mean skin temperatures of the groups $\left({ }^{\circ} \mathrm{C}\right)$.

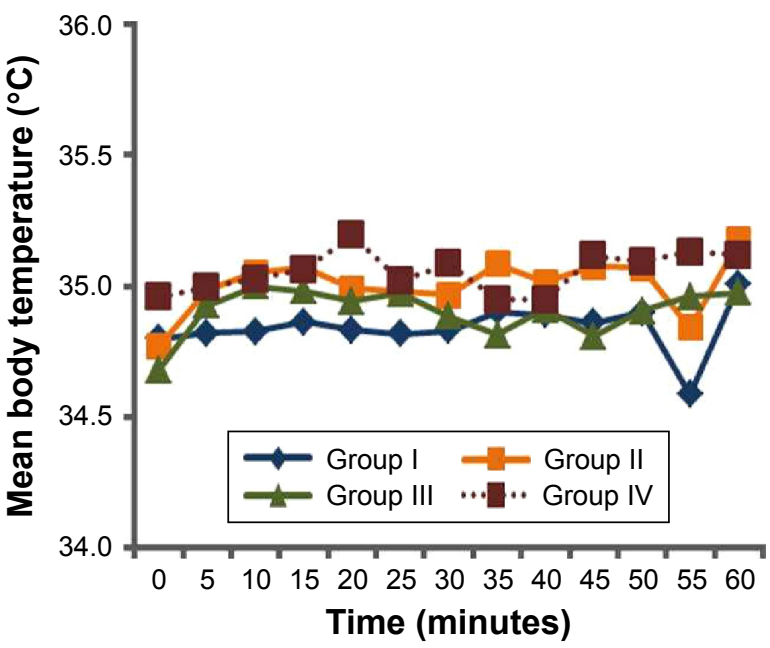

Figure 3 Mean body temperatures of the groups $\left({ }^{\circ} \mathrm{C}\right)$.

$1{ }^{\circ} \mathrm{C}-1.5^{\circ} \mathrm{C}$ during the first hour, and this hypothermia displays a slower and linear decrease during the rest of the time. Consequentially, temperature enters a plateau phase and the core temperature stays the same. ${ }^{2}$ In this study, we evaluated the effects of anesthesia on thermoregulation in obese patients, and found that tympanic temperature was higher in patients with higher BMIs, while MST and MBT did not change. Interestingly, vasoconstriction occurred later, and that vasoconstriction threshold was higher.

In a study that compared 10 obese patients with BMIs between 30.0 and 34.9 with 10 nonobese women with BMIs between 18.5 and 24.9 who have had abdominal surgeries, and received active heating methods, obesity was found to increase intraoperative core body temperature, decrease intraoperative hypothermia incidence, and cause higher core body temperature during awakening. ${ }^{10}$

In Kurz et al's study on 40 patients who had elective colon surgeries, they classified patients according to body fat percentages $(10 \%-24 \%, 25 \%-35 \%$, and $36 \%-50 \%)$ and body surface areas $\left(<35,36-44\right.$, and $\left.>45 \mathrm{~kg} / \mathrm{m}^{2}\right)$. They showed that the decrease in body temperature and amount of redistribution hypothermia was inversely related to body fat percentage and body surface area. ${ }^{11}$

In a study conducted on 10 obese (fat percentage $>25 \%$ ) and 10 nonobese $(<25 \%)$ male patients who underwent open abdominal surgery, core temperature, and vasoconstriction thresholds were shown to be higher in the obese patients. ${ }^{12}$

Savastano et al studied the relationship between adiposity and regional body temperatures in resting and thermoneutral conditions. ${ }^{13}$ They compared 13 patients with BMIs between 18-25 and 23 patients with BMIs $>30$. Using an infrared thermography method, they did not find any difference in the 
core temperature; however, they showed that abdominal skin temperature was lower and finger bed temperature was higher in obese patients. They declared that the huge abdominal subcutaneous fat tissue in the obese constituted a barrier that prevented heat transfer and protected from normothermia. In this study, we found that core temperature decreased in nonobese patients, and normothermia was better protected during anesthesia, which is known to disrupt thermoneutrality.

Boutet and Kassir have emphasized that BMI did not reflect the real metabolic profile of an obese patient. ${ }^{14}$ Another study showed that skin blood flow effectively shunts thermal insulation caused by the fat tissue, while others stated that BMI was significantly inversely correlated with skin vasodilation dependent on the endothelium. ${ }^{15,16}$

This study's major limitation is small sample size as in other studies in the literature. ${ }^{10-13}$

\section{Conclusion}

Obese patients who underwent laparoscopic bariatric surgery under general anesthesia were shown to have better core temperature protection, which was dependent on the degree of obesity. Contrary to all other unwanted effects of obesity in anesthesia practices, it was observed to relieve the negative effects of anesthesia on thermoregulation.

\section{Acknowledgment}

This article's abstract was presented in national congress (48. Turkish Anesthesiology and Reanimation Congress, December 2-6 2015, Antalya, Turkey).

\section{Disclosure}

The authors report no conflicts of interest in this work.

\section{References}

1. Sessler DI. Temperature monitoring. In: Miller RD, editor. Miller Anesthesia. Philadelphia: Churchill Livingstone; 2010:1367-1389.

2. Sessler DI. Perioperative heat balance. Anesthesiology. 2000;92(2): 578-596.

3. Steven MF, Kha MT, Lee AF. Clinical importance of body temperature in the surgical patient. $J$ Ther Biol. 2000;25(1-2):151-155.

4. Şahin A, Aypar Ü. Effect of amino acid solutions on intraoperative hypothermia and postoperative shivering. Acta Anaesthesiol Scand. 2002;46(1):64-67.

5. Shanks CA. Mean skin temperature during anaesthesia: an assessment of formulae in the supine surgical patient. Br J Anaesth. 1975;47(8): $871-876$

6. Ramanathan NL. A new weighting system for mean surface temperature of the human body. J Appl Physiol. 1964;19:531-533.

7. Burton AC. Human calorimetry: the average temperature of the tissues of the body. J Nutr. 1935;9:261-280.

8. Rubinstein EH, Sessler DI. Skin-surface temperature gradients correlate with fingertip blood flow in humans. Anesthesiology. 1990;73(3): 541-545.

9. Sessler DI. Skin-temperature gradients are a validated measure of fingertip perfusion. Eur J Appl Physiol. 2003;89(3-4):401-402.

10. Fernandes LA, Braz LG, Koga FA, et al. Comparison of peri-operative core temperature in obese and non-obese patients. Anaesthesia. 2012; 67(12):1364-1369.

11. Kurz A, Sessler DI, Narzt E, Lenhardt R, Lackner F. Morphometric influences on intraoperative core temperature changes. Anesth Analg. 1995;80(3):562-567.

12. Kasai T, Hirose M, Matsukawa T, Takamata A, Tanaka Y. The vasoconstriction threshold is increased in obese patients during general anaesthesia. Acta Anaesthesiol Scand. 2003;47(5):588-592.

13. Savastano DM, Gorbach AM, Eden HS, Brady SM, Reynolds JC, Yanovski JA. Adiposity and human regional body temperature. Am J Clin Nutr. 2009;90(5):1124-1131.

14. Boutet C, Kassir R. Sleeve gastrectomy and roux-en-Y gastric bypass lead to comparable changes in body composition after adjustment for initial body mass index. Obes Surg. 2016;26(8):1932-1933.

15. de Graaf AA, Freidig A, van Ommen B. Human thermoregulation and obesity. FASEB J. 2009;23(Suppl 1):596-602.

16. Caballero A, Arora S, Saouaf R, et al. Microvascular and macrovascular reactivity is reduced in subjects at risk for type 2 diabetes. Diabetes. 1999;48(9):1856-1862.
Therapeutics and Clinical Risk Management

\section{Publish your work in this journal}

Therapeutics and Clinical Risk Management is an international, peerreviewed journal of clinical therapeutics and risk management, focusing on concise rapid reporting of clinical studies in all therapeutic areas, outcomes, safety, and programs for the effective, safe, and sustained use of medicines. This journal is indexed on PubMed Central, CAS,

\section{Dovepress}

EMBase, Scopus and the Elsevier Bibliographic databases. The manuscript management system is completely online and includes a very quick and fair peer-review system, which is all easy to use. Visit $\mathrm{http}: / /$ www.dovepress.com/testimonials.php to read real quotes from published authors. 